\title{
PENGARUH TINGGI MUKA AIR TANAH PADA POPULASI SERANGGA DI LAHAN RAWA GAMBUT DESA KUALA DUA KABUPATEN KUBU RAYA
}

\author{
(Effect Of Water Level On Insect Populations On Peat Land Of Kuala Dua Village District Of \\ Kubu Raya)
}

\author{
Monica Evarina Situmorang, Dwi Astiani, Wiwik Ekyastuti \\ Fakultas Kehutanan Universitas Tanjungpura, Jalan Imam Bonjol Pontianak 78124 \\ monicasitumorang95@yahoo.com
}

\begin{abstract}
Insects are the most dominant group of animals living on the face of the earth and their role is ecologically significant. The purpose of the study was to observe the type of population and identify the effect of water level on the diversity of insect species found in the peat swamp area of Kuala Dua village. Data assesment was done by using survey method with systematic sampling. Observation plots was adjusted to the field conditions with water level 30, 40, 50 and $60 \mathrm{~cm}$. The results showed that there were 15 insects species belonging to 8 orders from 11 different families. The most common insects found in various TMAs that were observed, were Neurothemis fluctuan from the Odonata order. Physical conditions of the environment greatly affect the life of insects, such as having many types of plants which became food for insects. It can be concluded that the level of diversity of insect species has a relationship with environmental conditions such as vegetation, $\mathrm{pH}$, and water level.
\end{abstract}

Keywords: Insect population, systematic sampling, water level

\section{PENDAHULUAN}

Pengelolaan air di lahan gambut lebih sulit dilakukan, karena gambut memiliki konduktivitas hidrolik horizontal tinggi (Widjaja 2000), gambut secara fisik lembek serta memiliki daya menahan beban yang rendah (Nugroho et al.1997). Bila didrainase, lahan gambut akan mengalami subsiden (penurunan permukaan), dan potensial mengalami kering tidak balik (irriversible drying) dan berdampak terhadap penurunan kemampuan daya menahan airnya (hidrofobik), serta resiko ancaman kebakaran semakin tinggi. Pembukaan lahan gambut untuk pertanian/perkebunan tanpa diikuti usaha pengelolaan tata air yang bijak berdampak pada kerusakan dan meningkatkan emisi gas rumah kaca.

Tingkat keragaman serangga yang sangat tinggi dapat beradaptasi pada berbagai kondisi habitat, baik yang alamiah seperti hutan-hutan primer maupun habitat buatan manusia seperti lahan pertanian dan perkebunan (Siswanto dan Wiratno, 2001). Serangga dapat hidup di berbagai lingkungan diantaranya di lahan pertanian, semak, di lingkungan tempat tinggal, di lahan perkebunan dan lain sebagainya, mereka juga dapat berpindah tempat dari satu tempat ke tempat yang lain untuk mencari makanan bahkan terkadang tempat yang mereka datangi dapat rusak. 
Pembukaan hutan dan lahan gambut terjadi di Desa Kuala Dua Kabupaten Kubu Raya, pembukaan lahan untuk pertanian banyak disertai dengan membuat kanal untuk menurunkan tinggi muka air tanah gambut. Restorasi hidrologi yang dilakukan dengan menaikan tinggi muka air tanah dapat mempengaruhi keanekaragaman serangga yang ada di lahan rawa gambut tersebut. Namun bagaimana pengaruh tinggi muka air tanah terhadap kondisi populasi dan keragaman serangga belum diketahui, oleh karena itu penelitian pengaruh tinggi muka air tanah terhadap populasi serangga di lahan rawa gambut Desa Kuala Dua perlu dilakukan. Penelitian ini bertjuan untuk mendeskripsikan populasi dan keanekaragaman serangga dan lahan gambut desa Kuala Dua yang dipengaruhi tinggi muka air.

\section{Metode Penelitian}

Penelitian ini dilakukan di areal lahan gambut bekas kebakaran Desa Kuala Dua Kecamatan Sungai Raya Kabupaten Kubu Raya Kalimantan Barat, waktu penelitian 3 minggu efektif dilapangan. Bahan yang digunakan dalam penelitian ini adalah alkohol $70 \%$, air garam, terasi, dan aquades sedangkan alat yang dipakai adalah peta lokasi, alat tulis, loupe, pinset, cangkul, meteran, jaring serangga, gelas plastik, botol koleksi basah serangga, sarung tangan, buku kunci determinasi serangga, dan kamera.

Objek yang diteliti adalah seluruh serangga yang ditemukan di area lahan gambut yang aktif di permukaan tanah, di dalam tanah, dan serangga yang aktif terbang di areal lahan gambut bekas kebakaran, data yang dikumpulkan dalam penelitian ini adalah data yang didapatkan dari pengukuran dan pengamatan langsung di lapangan, berupa data serangga yang berhasil ditangkap menggunakan perangkap dan yang ditangkap langsung dengan tangan atau bantuan jaring serangga. Penelitian yang dilakukan bersifat observasi lapangan dengan metode survei, pengambilan data penelitian dilakukan dengan menggunakan sistematis sampling. Dasar pembuatan plot pengamatan disesuaikan dengan kondisi lapangan yaitu area terbuka lahan gambut bekas kebakaran, yang diletakan dengan secara berurutan yaitu dari mulai pinggir dome dengan tinggi muka air 30, 40, 50, dan $60 \mathrm{~cm}$.

Sebelum penelitian dilaksanakan, survei awal dilakukan untuk melihat keadaan lokasi penelitian seperti keadaan lingkungan banjir atau kering, jika terjadi banjir penelitian tidak bisa dilaksanakan karena sampel tidak bisa didapatkan dalam kondisi lingkungan tergenang air dan jebakan yang dipasang dapat terganggu, lokasi ada di empat petak pengamatan yang diletakan secara purposive, peletakan petak didasarkan pada tinggi muka air yang berbeda tinggi muka air tersebut adalah $30 \mathrm{~cm}, 40 \mathrm{~cm}, 50 \mathrm{~cm}$ dan $60 \mathrm{~cm}$ dari permukaan tanah, luasan masingmasing tiap TMA adalah $5000 \mathrm{~m}^{2}$ .Pengambilan sampel menggunakan tiga teknik yaitu menggunakan jaring, untuk menangkap serangga yang aktif terbang, 
kemudian dengan cara menggali untuk mendapatkan serangga yang aktif di dalam tanah dan yang terakhir dengan menggunakan pitfall trap untuk menangkap serangga yang aktif di permukaan tanah.

Identifikasi serangga dengan cara menghitung jumlah kepadatan populasi serangga dengan rumus yaitu jumlah individu per satuan luas (Fachrul 2007) selanjutnya indeks keanekaragaman dihitung dengan menggunakan rumus dari Shannon-Wiener $\mathbf{H}^{\prime}=-\sum$ Pi In Pi.

\section{Hasil dan Pembahasan}

Hasil dari penelitian di areal lahan rawa gambut bekas kebakaran pada berbagai tinggi muka air tanah di desa Kuala Dua kecamatan Sungai Raya kabupaten Kubu Raya, berdasarkan empat perlakuan pada tinggi muka air $30 \mathrm{~cm}, 40 \mathrm{~cm}, 50 \mathrm{~cm}$, dan $60 \mathrm{~cm}$ dengan lima kali pengulangan terdapat 15 jenis serangga yang tergolong kedalam 8 ordo dari 11 famili yang berbeda.

Tabel 1. Populasi serangga di areal lahan gambut pada berbagai tinggi muka air tanah (TMA) (Insect population in peatland areas at various soil water levels).

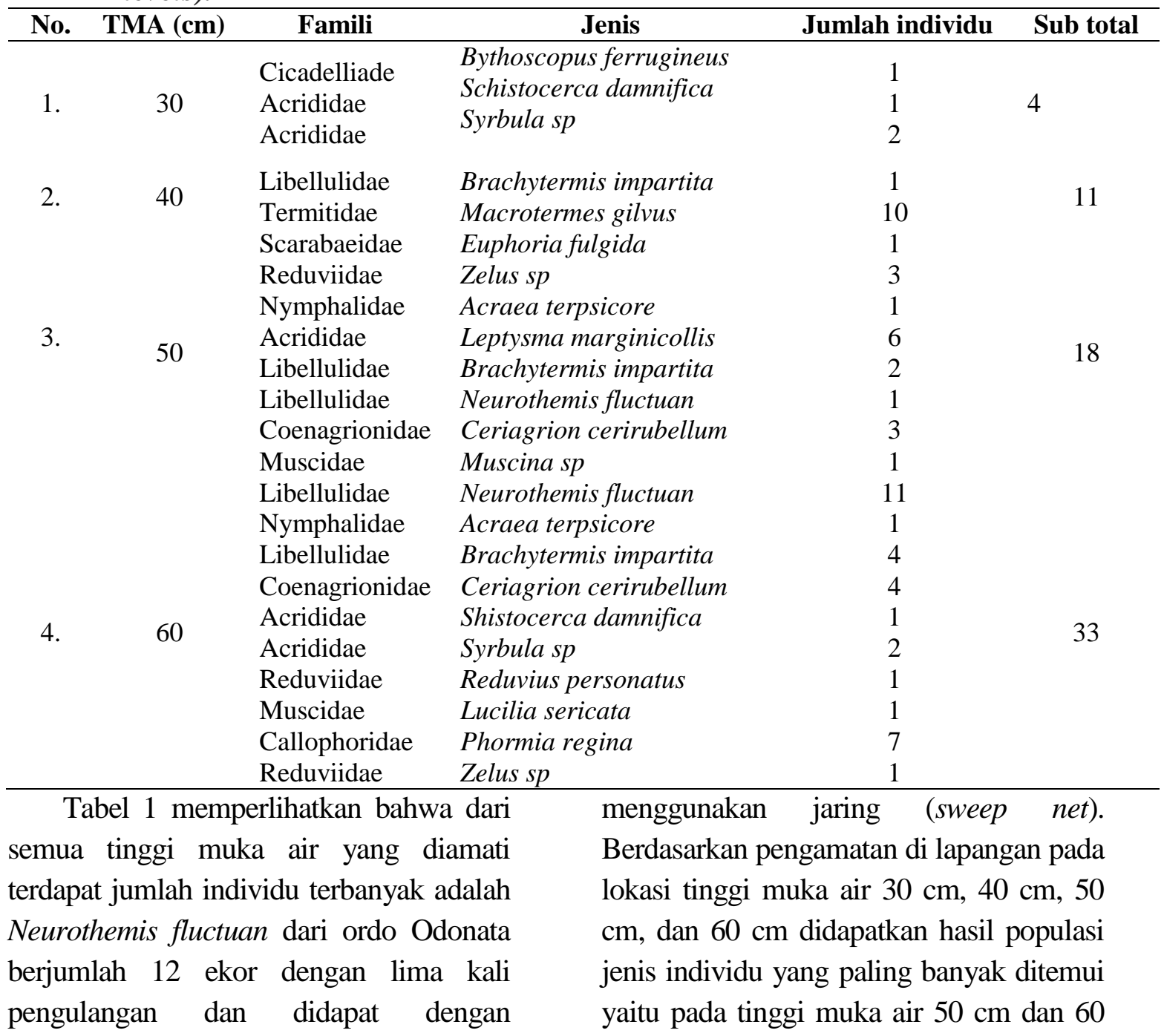


$\mathrm{cm}$ hasil bisa dilihat pada Tabel 1. Tinggi muka air $30 \mathrm{~cm}$ dan $40 \mathrm{~cm}$ sangat sedikit sekali ditemukan jenis individu dibandingkan dengan tinggi muka air 50 $\mathrm{cm}$ dan $60 \mathrm{~cm}$ karena perbedaaan beberapa faktor seperti vegetasi, $\mathrm{pH}$, suhu dan lingkungan, pada tinggi muka air $30 \mathrm{~cm}$ dan $40 \mathrm{~cm}$ memiliki kondisi lingkungan yang sama yaitu memiliki vegetasi tumbuhan nanas karena pada areal tinggi muka air ini adalah kebun nanas warga setempat dan ada juga tumbuhan perdu, kedua lokasi ini memiliki temperatur $32^{\circ} \mathrm{C}$ dengan $\mathrm{pH}$ masing-masing 3,25 pada tinggi muka air $30 \mathrm{~cm}$ dan $\mathrm{pH} \mathrm{3,27} \mathrm{pada}$ tinggi muka air $40 \mathrm{~cm}$ pada kedua lokasi ini sangat sedikit sekali ditemukan populasi serangga karena kurangnya bahan makanan dan lingkungan yang kering menyebabkan hanya beberapa serangga yang mampu hidup di tempat ekstrim seperti pada tinggi muka air $30 \mathrm{~cm}$ serangga yang dominan ditemukan di lokasi ini dari ordo Orthopthera yaitu Syrbula $s p$ dengan teknik pengambilan individu menggunakan jaring,jenis ini ditemukan sebanyak 2 individu sangat sedikit karena sejalan dengan Untung (1996) kelimpahan serangga akan berkurang ketika sumber makanan, tempat berlindung, tempat kawin, dan faktor lingkungan lainnya tidak mencukupi.

Tinggi muka air $50 \mathrm{~cm}$ dan $60 \mathrm{~cm}$ didapat banyak populasi jenis serangga karena di lokasi ini memiliki banyak jenis tumbuhan yang merupakan salah satu habitat serangga adapun beberapa tumbuhan yang ditemui pada kedua lokasi ini ialah ilalang (Imperata cylindrica L.) dan pakis (Stenochama polushis L.) keadaan vegetasi dari lahan gambut terdiri dari berupa tumbuhan pohon, perdu, semak hingga rumput hal ini juga mempengaruhi untuk kelangsungan hidup serangga, perbedaan tumbuhan antara kedua lokasi ini adalah pada tinggi muka air $50 \mathrm{~cm}$ terdapat ilalang yang sudah mati bekas kebakaran, kedua lokasi ini memiliki $\mathrm{pH}$ sedikit lebih rendah yaitu 3,04 pada tinggi muka air $50 \mathrm{~cm}$ dan 3,07 pada tinggi muka air $60 \mathrm{~cm}$ dan temperatur $32^{0} \mathrm{C}$.

Serangga yang ditemukan pada tinggi muka air $50 \mathrm{~cm}$ terdiri atas 7 ordo yang terbagi dalam 7 famili dengan total keseluruhan individu adalah 18 ekor, serangga yang paling banyak ditemukan di lokasi ini adalah Leptysma marginicollis yang berjumlah 6 ekor dengan teknik pengambilan menggunakan jaring,yang termasuk dalam ordo Orthoptera.

Pada tinggi muka air $60 \mathrm{~cm}$ terdapat 8 ekor serangga yang aktif di permukaan tanah lokasi ini hampir sama dengan lokasi tinggi muka air $50 \mathrm{~cm}$ bedanya lokasi ini memiliki lebih beragam vegetasi seperti tumbuhan paku-pakuan, serangga yang aktif di permukaan tanah kurang ditemui karena sama juga halnya dengan lokasi tinggi muka air $50 \mathrm{~cm}$ yang memiliki kelembapan tanah yang tinggi sehingga jenuh air, intensitas cahaya yang cukup tinggi dan tidak adanya vegetasi pohon sehingga lokasi ini menjadi panas beberapa serangga.

Pengaruh tinggi muka air tanah terhadap populasi serangga yang aktif terbang di lahan rawa gambut bekas kebakaran Desa Kuala Dua Kabupaten Kubu Raya 
Serangga yang paling banyak tertangkap didominasi oleh serangga dari ordo Odonata yang banyak didapat pada tinggi muka air $60 \mathrm{~cm}$ hal ini dikarenakan kondisi lingkungan di lokasi ini memiliki vegetasi yang banyak ditumbuhi oleh alang-alang dan paku-pakuan sebagai bahan makanan serangga sehingga pada tinggi muka air $60 \mathrm{~cm}$ banyak terdapat berbagai jenis serangga, vegetasi yang hidup di perairan tawar juga berperan sebagai tempat meletakan telur bagi sebagian besar jenis capung begitu juga menurut Shanti Susanti (1998) capung identik dengan kawasan perairan tawar karena capung menghabiskan sebagian besar hidupnya sebagai nimfa yang sangat bergantung pada habitat perairan tawar, dan tidak ditemukan satu jenis pun capung yang hidup di laut, namun ada beberapa yang tahan terhadap tingkat garam tertentu, dan ada juga nimfa capung hutan tropis yang hidup di darat.

Tabel 2. Kepadatan populasi jenis serangga terbang di areal lahan gambut pada berbagai tinggi muka air tanah (TMA) (Population density of insect species flying on peatland areas at various soil water levels).

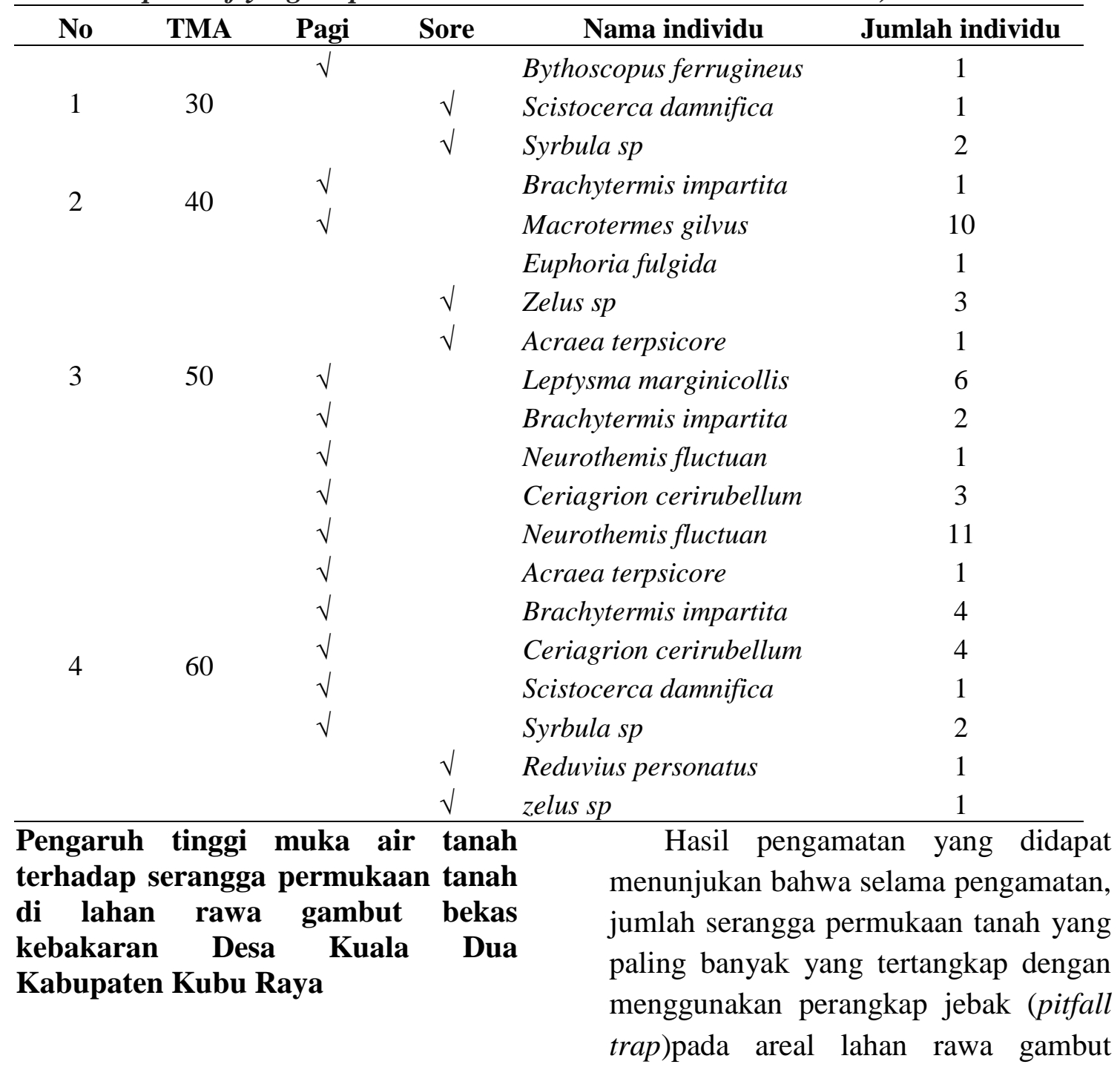


bekas kebakaran adalah serangga dari ordo Diptera, keberadaan serangga tanah pada suatu ekosistem dibatasi oleh faktor-faktor geologi dan ekologi yang cocok, sehingga terjadi perbedaan keanekaragaman jenis serangga.

Tabel 3. Kepadatan populasi serangga dalam jebakan di areal lahan gambut pada berbagai tinggi muka air (TMA) (Insect density found in traps in peatland areas at various water levels).

\begin{tabular}{cccccccc}
\hline No & TMA & Hari 1 & Hari 2 & Hari 3 & Hari 4 & Hari 5 & $\sum$ Individu \\
\hline 1 & $30 \mathrm{~cm}$ & 0 & 0 & 0 & 0 & 0 & 0 \\
2 & $40 \mathrm{~cm}$ & 0 & 0 & 0 & 0 & 0 & 0 \\
3 & $50 \mathrm{~cm}$ & 1 & 0 & 0 & 0 & 0 & 1 ekor \\
4 & $60 \mathrm{~cm}$ & 6 & 1 & 1 & 0 & 0 & 8 ekor \\
\hline \multicolumn{2}{l}{ Tabel } & 3 & menunjukan & hasil & menyebabkan & proses & jaring-jaring
\end{tabular}

kepadatan populasi serangga dalam jebakan pada tinggi muka air $30 \mathrm{~cm}, 40$ $\mathrm{cm}, 50 \mathrm{~cm}$ dan $60 \mathrm{~cm}$ adapun serangga yang didapat adalah Muscina sp yang terdapat pada tinggi muka air $50 \mathrm{~cm}$ dan Phormia regina yang terdapat pada tinggi muka air $60 \mathrm{~cm}$ dengan lima kali ulangan. Tinggi muka air $60 \mathrm{~cm}$ paling banyak ditemukan serangga dengan teknik jebakan ini ada sebanyak 7 ekor dengan kondisi banyaknya vegetasi sebagai bahan makanan, tinggi muka air yang tidak terlalu kering sehingga serangga yang di atas tanah pun dapat bertahan hidup, kehadiran serangga tanah dapat dijadikan sebagai indikator keseimbangan ekosistem. Artinya apabila dalam ekosistem tersebut diversitas serangga tinggi maka dapat dikatakan lingkungan ekosistem tersebut seimbang atau stabil, diversitas serangga tanah yang tinggi akan makanan berjalan secara normal begitu sebaliknya apabila di dalam ekosistem diversitas serangga rendah maka lingkungan ekosistem tersebut tidak seimbang dan labil (Suheriyanto, 2008).

Pengaruh tinggi muka air tanah terhadap serangga tanah di lahan rawa gambut bekas kebakaran Desa Kuala Dua Kabupaten Kubu Raya

Hasil pengamatan menunjukan bahwa serangga tanah banyak ditemukan di dalam tanah dengan kedalaman 1-10 cm, serangga tanah yang banyak ditemukan adalah dari ordo Isoptera yang banyak didapat pada tinggi muka air tanah $40 \mathrm{~cm}$ dengan jumlah 11 ekor hasil ini didapat dengan cara menggali tanah dengan ukuran 10x10x10 cm,lokasi ini adalah lahan terbuka yang didominasi oleh tumbuhan nanas dan banyak sisa-sisa kayu yang telah busuk bekas kebakaran. 
Tabel 4. Kepadatan populasi serangga di dalam tanah di areal lahan gambut pada berbagai tinggi muka air tanah (TMA) (Insect population density in soil in peatland areas at various soil water levels).

\begin{tabular}{|c|c|c|c|c|c|c|c|c|}
\hline No & TMA & $\begin{array}{c}\text { Kotak } \\
\text { I }\end{array}$ & $\begin{array}{c}\text { Kotak } \\
\text { II }\end{array}$ & $\begin{array}{c}\text { Kotak } \\
\text { III }\end{array}$ & $\begin{array}{c}\text { Kotak } \\
\text { IV }\end{array}$ & Kotak V & $\sum_{\text {Individu }}$ & $\begin{array}{c}\text { Kepadatan } \\
\text { populasi } \\
\text { ekor } / \mathrm{m} 2 \\
\end{array}$ \\
\hline 1 & $30 \mathrm{~cm}$ & 0 & 0 & 0 & 0 & 0 & 0 & 0 \\
\hline 2 & $40 \mathrm{~cm}$ & 0 & 0 & 0 & 0 & 11 ekor & 11 ekor & 0,22 \\
\hline 3 & $50 \mathrm{~cm}$ & 0 & 0 & 0 & 0 & 0 & 0 & 0 \\
\hline 4 & $60 \mathrm{~cm}$ & 0 & 0 & 0 & 0 & 0 & 0 & 0 \\
\hline
\end{tabular}

kepadatan populasi serangga yang ada di dalam tanah yang hanya ditemukan pada tinggi muka air tanah $40 \mathrm{~cm}$ saja lokasi ini adalah kebun nanas warga dengan kondisi lingkungan sedikitnya vegetasi pohon, tumbuhan alang-alang dan tumbuhan paku-pakuan di lokasi ini banyak ditemukan sisa-sisa kayu yang telah busuk yang mati bekas kebakaran. Jenis yang ditemukan di tinggi muka air tanah $40 \mathrm{~cm}$ ini adalah rayap ditemukan di sisa-sisa kayu yang telah mati, karena rayap tidak dapat hidup di tempat yang terlalu kering hal ini sejalan dengan Nandika et al (2003) yang mengatakan bahwa rayap tidak dapat perilaku rayap tanah yang tidak menyukai tempat yang terlalu kering.

Indeks keanekaragaman serangga yang ada di lahan rawa gambut pada berbagai TMA di desa Kuala Dua kabupaten Kubu Raya.

Tabel 5. Indeks keanekaragaman serangga di lahan rawa gambut bekas kebakaran (Diversity index of insects on peat swamp land of fire).

\begin{tabular}{cccc}
\hline No. & TMA (cm) & Jumlah individu & Indeks keanekaragaman (H') \\
\hline 1. & 30 & 4 & 1,04 \\
2. & 40 & 11 & 0,30 \\
3. & 50 & 18 & 1,85 \\
4. & 60 & 33 & 1,91 \\
\hline
\end{tabular}

Hasil perhitungan indeks

keanekaragaman (H') menunjukkan bahwa pada TMA $60 \mathrm{~cm}$ cenderung lebih tinggi yaitu 1,91 kemudian pada TMA $50 \mathrm{~cm}$ memiliki nilai hampir sama yaitu 1,85. Pada TMA $30 \mathrm{~cm}$ dan $40 \mathrm{~cm}$ indeks keanekaragaman serangga cenderung lebih menurun. Indeks keanekaragaman pada tiga TMA $30 \mathrm{~cm}$, $50 \mathrm{~cm}$ dan $60 \mathrm{~cm}$ tersebut dikategorikan sedang karena kondisi lingkungan tersebut memiliki tingkat ekosistem yang mendukung suatu kehidupan serangga salah satu faktornya adalah vegetasi dan kondisi iklim mikro yang lebih menunjang kehidupan serangga yang ada di lokasi tersebut.

\section{Kesimpulan}

Hasil penelitian tentang populasi serangga pada tinggi muka air tanah 30 $\mathrm{cm}$ berjumlah 4 ekor, tinggi muka air 40 $\mathrm{cm}$ berjumlah 11 ekor, kemudian tinggi muka air $50 \mathrm{~cm}$ berjumlah 18 ekor dan tinggi muka air $60 \mathrm{~cm}$ berjumlah 33 ekor. Semakin tinggi muka air tanah, cenderung meningkatkan populasi serangga. Total populasi serangga pada tinggi muka air tanah $60 \mathrm{~cm}$ meningkat 
lebih besar sembilan kali lipat dibanding dengan tinggi muka air 30 $\mathrm{cm}$.

\section{Saran}

Diharapkan adanya penelitian perbandingan populasi serangga di lahan gambut terbuka bekas kebakaran dengan populasi serangga yang ada di hutan primer sebagai pembanding.

\section{Daftar Pustaka}

Facrul MF. 2007. Metode Sampling Bioekologi. Bumi Aksara. Jakarta

Nandika D, Rismayadi Y, Diba F. 2003. Rayap Biologi dan Pengendaliannya. Universitas Muhammadiyah Surakarta. Surakarta.

Nugroho KG, Gianinazzi, Widjaja Adhi. 1997. Soil hidraulic properties of Indonesian peat. In: Rieley and Page (Eds.). pp. 147156 In Biodiversity and sustainability of tropical peat and peatland. Samara Publishing Ltd. Cardigan. UK.

Susanti Shanti. 1998. Seri Panduan Lapangan: Mengenal Capung. Puslitbang Biologi-LIPI. Bogor.

Siswanto, Wiratno. 2000. Biodervisitas serangga pada tanaman panili (Vlanillaplanipolia) dengan tanaman penutup tanah Arachis pintoi K. (Proseding Seminar Nasional III). Perhimpunan Entomologi Indonesia. Bogor.

Suheriyanto, Dwi. 2008. Ekologi Serangga. UIN Press. Malang

Untung, K. 1996. Pengantar Pengelolaan Hama Terpadu. Gadjah Mada University Press. Yogyakarta. 